\title{
Rancang Bangun Sistem Informasi Penjualan Berbasis Web pada Smooth-Tee dengan Metode Waterfall
}

\author{
Aryo Tunjung Kusumo ${ }^{1}$, Vito Triantori ${ }^{2}$, Ishak Komarudin ${ }^{3}$
}

\begin{abstract}
Information has quickly become a hallmark in this era of globalization, thanks to sophistication technology and scientific development. Information and technology can build an era that smart and modern. Smooth-tee is a shop that sells clothes is still operating using conventional methods, seen from the way of sales promotion, processing order data is still recorded manually and this will certainly hinder the development of the company to obtain information about order data, allowing for miscalculation, data loss, or corruption due to no manual backup of archive data. From these problems, the authors are interested in designing a web-based information system. The author uses the method interviews, observations and waterfalls. Application are created using MySQL for the databases and PHP Programming as a tool for making information system, This system can help to make reports well. Sales information system design aims to respond to needs fast information for users quickly, precisely and effectively.
\end{abstract}

Intisari- Informasi dengan cepat telah menjadi ciri khas di era globalisasi ini, berkat kecanggihan teknologi dan perkembangan ilmu pengetahuan. Informasi dan teknologi dapat membangun zaman yang. Smooth-tee merupakan toko yang menjual baju masih beroperasi menggunakan cara konvensional, dilihat dari cara promosi penjualannya, pengolahannya data pesanan masih tercatat secara manual dan hal ini tentunya akan menghambat perkembangan perusahaan untuk mendapatkan informasi tentang data pesanan, memungkinkan adanya salah perhitungan, kehilangan data, atau rusak karena tidak adanya pencadangan data arsip manual. Dari permasalahan tersebut, penulis tertarik untuk merancang sistem informasi berbasis web. Dalam penulisan ini, penulis menggunakan metode wawancara, observasi dan waterfall. Aplikasi yang dibuat menggunakan MySQL untuk database dan pemrograman PHP sebagai alat bantuk pembuatan sistem informasi tersebut. Desain sistem informasi penjualan bertujuan untuk merespon kebutuhan informasi cepat untuk pengguna secara cepat, tepat dan efektif.

Kata Kunci- Sistem Informasi, Penjualan, Waterfall, PHP, Codeigniter

${ }^{1}$ Program Studi Sistem Informasi Kampus Kabupaten Karawang Universitas Bina Sarana Informatika, Jln. Banten No.1, Karangpawitan, Kec. Karawang Barat, Kabupaten Karawang, Jawa Barat 41351 tlp: (0267) 8454893,email: aryo.atk@bsi.ac.id

${ }^{2}$ Program Studi Sistem Informasi STMIK Nusamandiri Jakarta, Jln. Jatiwaringin Raya No.02 RT08 RW 013 Kelurahan Cipinang Melayu Kecamatan Makassar Jakarta Timur 13620 tlp: 02128534236.email: vito.vto@nusamandiri.ac.id

${ }^{2}$ Program Studi Sistem Informasi Universitas Bina Sarana Informatika Jakarta, Kampus Kramat $98 \mathrm{Jl}$. Kramat Raya No.98, Senen, Jakarta Pusat 10450 tlp: $\quad$ (021) 23231170, email: ishak.komarudin@bsi.ac.id.

\section{PENDAHULUAN}

Di masa pandemi seperti saat ini cukup banyak bisnis yang terdampak dikarenakan bisnis tersebut berjalan secara offline dalam arti membuka toko yang berakibat bisnis atau toko tersebut tutup karena jarangnya konsumen untuk datang langsung sehingga pendapatan sangat berkurang tetapi banyak pengeluaran-pengeluaran yang harus dilakukan mulai dari membayar sewa toko sampai membayar tagihan listrik dan air.

Dengan melihat permasalahan tersebut toko Smooth-Tee yang mempunyai bisnis penjualan baju kaos mempunyai rencana untuk membangun aplikasi penjualan secara online dengan basis HTML dan PHP. Agar dapat menekan pengeluaran untuk sewa toko, tagihan llistrik serta tagihan air dan memaksimakan pendapatan dengan website yang dapat dikelola sendiri.

Pemanfaatan teknologi informasi seperti ini juga selaras dengan kebijakan pemerintah di masa pandemi ini dimana orang-orang tidak boleh berkerumun dan mengurangi kegiatankegiatan di luar rumah, sehingga konsumen mulai beralih lebih banyak belanja secara online. Selain itu dengan penjualan secara online maka membuka peluang untuk menjual produknya ke seluruh Indonesia bahkan dunia.

Berdasarkan latar belakang masalah maka penulis membatasi ruang lingkup penelitian. Adapun batasan ruang lingkupnya membahas tentang proses pemesanan, pengelolaan pesanan dan pengelolaan produk oleh admin. Peralatan yang digunakan untuk membangun sistem ini menggunakan aplikasi Sublime Text 3 untuk text editornya, MySQL untuk merancang database serta Codeigniter sebagai framework website.

\section{TINJAUAN PUSTAKA}

\section{A. Pengertian Sistem Informasi}

Suatu sistem pada dasarnya adalah sekelompok unsur yang erat hubungannya satu dengan yang lain, yang berfungsi bersama-sama untuk mencapai tujuan tertentu. [1] Sistem mengandung arti kumpulan-kumpulan dari komponenkomponen yang dimiliki unsur keterkaitan antara satu dengan yang lainnya. [4] Sistem adalah kumpulan elemen yang saling berhubungan dan saling berinteraksi satu sama lain untuk mencapai satu tujuan tertentu. [2]

\section{B. Karakeristik Sistem}

Suatu sistem mempunyai beberapa karakteristik, yaitu komponen sistem, batasan sistem, lingkungan luar sistem, penghubung sistem, masukan sistem, keluaran sistem, pengolah sistem, dan sasaran sistem. [3]

C. Konsep Informasi 
Informasi adalah data yang telah diolah menjadi suatu bentuk yang penting bagi si penerima dan mempunyai nilai nyata atau yang dapat dirasakan dalam keputusan-keputusan yang sekarang atau keputusankeputusan yang akan dating. [4] Nilai dari informasi ditentukan dari 2 (dua) hal, yaitu manfaat dan biaya untuk mendapaatkannya. Suatu informasi dapat dikatakan bernilai apabila manfaat yang diperoleh lebih berharga dibandingkan dengan biaya untuk mendapatkannya. [3] Kualitas dari suatu informasi tergantung dari 3 (tiga) hal, yaitu informasi harus akurat (accurate), tepat waktu (timelines), dan relevan (relevance).

Fungsi utama informasi adalah untuk menambah pengetahuan atau mengurangi ketidak pastian pemakai informasi, karena informasi berguna memberikan gambaran tentang sesuatu permasalahan sehingga pengambil keputusan dapat menentukan keputusan lebih cepat, informasi juga memberikan standar, aturan maupun indikator bagi pengambil keputusan.

\section{Konsep Dasar Sistem Informasi}

Sistem informasi adalah suatu sistem didalam suatu organisasi yang mempertemukan kebutuhan pengolahan transaksi harian yang mendukung fungsi operasi organisasi yang bersifat manajerial dengan kegiatan strategi dari suatu organisasi untuk dapat menyediakan laporan-laporan yang diperlukan oleh pihak luar tertentu. [5]

Sistem informasi terdiri dari komponen yang disebut dengan istilah blok bangunan (building block), yang terdiri dari blok masukan, blok model, blok keluaran, blok teknologi, blok basis data, dan blok kendali. [7]

1. Blok masukan (input block)

Input mewakili data yang masuk ke dalam sistem informasi. Input disini termasuk metode-metode dan media yang digunakan untuk menangkap data yang akan dimasukkan, yang dapat berupa dokumen dasar. [5]

2. Blok model (model block)

Blok ini terdiri dari kombinasi prosedur, logika, dan model matematik yang akan memanipulasi data input dan data yang tersimpan di basis data dengan cara yang sudah tertentu untuk menghasilkan keluaran yang diinginkan. [8]

3. Blok keluaran (output block)

Produk dari sistem informasi adalah keluaran yang merupakan informasi yang berkualitas dan dokumentasi yang berguna untuk semua tingkatan manajemen serta semua pemakai sistem. [5]

4. Blok teknologi (technology block)

Teknologi digunakan untuk menerima input, menjalankan model, menyimpan dan mengakses data menghasilkan dan mengirimkan keluaran dan membantu pengendalian sistem secara keseluruhan. Teknologi terdiri dari unsur utama: [6]

a) Teknisi (human ware atau brain ware)

b) Perangkat lunak (software)

c) Perangkat keras (hardware)

5. Blok basis data (database block)
Basis data (database) merupakan kumpulan data yang saling berhubungan satu dengan yang lainnya, tersimpan diperangkat keras komputer dan digunakan untuk memanipulasinya. [7]

6. Blok Kendali (control block)

Banyak faktor yang dapat merusak sistem informasi, misalnya bencana alam, api, temperature tinggi, air, debu, kecurangan-kecurangan, kejanggalan sistem itu sendiri, kesalahan-kesalahan, ketidak-efisienan, sabotase, dan lain sebagainya.

Beberapa Pengendalian perlu dirancang dan diterapkan untuk meyakinkan bahwa hal-hal yang dapat merusak sistem dapat dicegah dan bila terlanjur terjadi kesalahan dapat langsung diatasi.

\section{E. Pengujian Kotak Hitam (Black-BoxTesting)}

Menguji perangkat lunak dari segi spesifkasi fungsional tanpa menguji desain dan kode program. Pengujian dimaksudkan untuk mengetahui apakah fungsi-fungsi, masukan, dan keluaran dari perangkat lunak sesuai dengan spesifikasi yang dibutuhkan [9]. Pengujian kotak hitam dilakukan dengan membuat kasus uji yang bersifat mencoba semua fungsi dengan memakai perangkat lunak apakah sesuai dengan spesifikasi yang dibutuhkan.

Kasus uji yang dibuat untuk melakukan pengujian kotak hitam harus dibuat dengan kasus benar dan kasus salah, misalkan untuk kasus login maka kasus uji yang dibuat adalah [9]:

1) Jika user memasukkan nama pemakai (username) dan kata sandi (password) yang benar.

2) Jika user memasukkan nama pemakai (username) dan kata sandi (password) yang salah, misalnya nama pemakai benar dan kata sandi salah, atau sebaliknya, atau keduanya salah.

\section{F. Peralatan Pendukung (Tools System)}

1. Unified Modeling Language (UML)

Unified Modeling Language (UML) merupakan Bahasa visual untuk pemodelan dan komunikasi mengenai sebuah sistem dengan menggunakan diagram dan teks-teks pendukung [9].

Berikut diagram dalam Unified Modeling Language(UML)

a. Use Case Diagram

Use case diagram merupakan pemodelan untuk melakukan (behavior) sistem informasi yang akan dibuat. Use case mendeskripsikan sebuah interaksi antara satu atau lebih aktor dengan sistem informasi yang akan dibuat. Secara kasar, use case digunakan untuk mengetahui fungsi apa saja yang ada dalam sebuah system informasi dan siapa saja yang berhak mengunakan fungsi tersebut. Syarat penamaan pada use case adalah nama didefinisikan sesimpel mungkin dan dapat dipahami. Ada dua hal utama pada use case yaitu pendefinisian yang disebut aktor dan use case. Aktor merupakan orang, proses, sistem lain yang berinteraksi dengan sistem informasi yang akan dibuat di luar sistem informasi yang dibuat itu sendiri, jadi walaupun simbol dari aktor adalah gambar orang, 
tapi aktor belum tentu adalah orang. Use case merupakan fungsionalitas yang disediakan sistem sebagai unit-unit yang saling bertukar pesan antar unit atau aktor.

b. Activity Diagram

Activity diagram dapat digunakan untuk menggambarkan bagaimana kegiatan dikoordinasikan untuk menyediakan layanan pada berbagai tingkat abstraksi. Karena activity diagram mendukung dan mendorong perilaku paralel. Activity diagram juga dapat menggambarkan tautan ke suatu objek dengan memberi label aktivitas dengan nama objek atau dengan menggunakan "swimlame", yang memungkinkan diagram aktivitas disusun berdasarkan tanggung jawab.

\section{c. Class Diagram}

Class Diagram menggambarkan struktur sistem dari segi pendefinisien kelas-kelas yang akan dibuat untuk membangun sistem kelas memiliki apa yang disebut atribut dan metode dan operasi.

1) Atribut merupakan variable-variabel yang dimiliki oleh suatu kelas.

2) Operasi atau metode adalah fungsi-fungsi yang dimiliki oleh suatu kelas.

Diagram kelas dibuat agar pembuat program atau programmer membuat kelas-kelas sesuai rancangan didalam diagram kelas agar antara dokumentasi perancangan dan perangkat lunak sinkron. Banyak berbagai kasus, perancangan kelas yang dibuat tidak sesuai dengan kelas-kelas yang dibuat pada perangkat lunak, sehingga tidaklah ada gunanya lagi sebuah perancangan karena karena apa yang dirancang dan hasil jadinya tidak sesuai.

\section{Metode PENELITIAN}

Untuk menyelesaikan penelitian ini penulis melakukan dua tahap penyelesaian yaitu,

A. Metode Pengumpulan Data

1. Pengamatan (Observation)

Metode ini adalah pengumpulan data yang dilakukan penulis dengan cara mengamati secara langsung semua kegiatan dalam sistem penjualan pada Smooth-Tee yang kemudian diteliti sehingga dapat diketahui proses bisnis dan kesalahan dari kegiatan tersebut.

2. Wawancara (Interview)

Metode ini adalah pengumpulan data dengan cara tanya jawab secara langsung untuk mendapatkan kelengkapan data dan dokumen yang terkait dengan sistem penjualan yang terdapat di toko tersebut.

3. Studi Pustaka

Selain kegiatan di atas, penulis juga melakukan studi pustaka guna mendukung dan memperlengkap data yang didapat, berupa referensi dari buku dan jurnal agar lebih relevan dengan topik atau pokok masalah yang sedang penulis teliti.

\section{B. Model Pengembangan Sistem}

Model pengembangan yang digunakan dalam skripsi ini adalah dengan menggunakan model pengembangan waterfall. Metode waterfall terdiri dari beberapa langkah, yaitu:

1. Analisa Kebutuhan Sistem
Dalam tahapan ini dilakukan analisa kebutuhan sistem, wawancara atau lainnya guna mendapatkan data-data yang diinginkan. Dengan adanya data-data terkumpul dapat membantu dalam merancang sebuah sistem.

2. Desain

Desain merupakan gambaran usulan perangkat lunak seperti struktur data, arsitektur perangkat lunak, representasi interface, dan prosedur pengkodean. Pada penelitian ini, desain sistem yang digunakan menggunakan tools UML ( use case diagram, activity diagram \& class diagram ).

\section{Code Generation}

Pada tahap ini, penulis membuat program menggunakan pemrograman yang terstruktur dan menggunakan phpMyAdmin untuk database MySQL.

4. Testing

Pengujian terhadap sebuah program yang telah dibuat. Hal ini dilakukan untuk mengetahui apakah ada kesalahan dan memastikan keluaran yang dihasilkan sesuai dengan yang diinginkan. Pengujian yang dilakukan menggunakan Black Box Testing.

\section{HASIL DAN PEMBAHASAN}

\section{A. Hasil Analisa}

Berdasarkan analisa, penulis menemukan permasalahan yang ada pada Smooth-Tee sebagai berikut :

1) Belum adanya media digital seperti website yang memudahkan Pembeli untuk order.

2) Data transaksi masih manual dan belum memiliki data elektronik yang berguna untuk backup, jika terjadi kehilangan data.

3) Masih minimnya media promosi, hanya mengandalkan brosur yang disebar.

Untuk menyelesaikan masalah yang ada, maka penulis mengusulkan pembuatan Sistem Informasi Penjualan berbasis Web diantaranya:

1) Membuat sistem pemesanan secara online, sehingga memudahkan customer untuk order.

2) Membuat manajemen data transaksi yang rapih dan dapat di backup dalam bentuk digital.

3) Membantu perluasan jangkauan pemasaran, dengan memanfaatkan media website yang mudah di akses kapanpun, di manapun.

4) Mengimplementasikan perancangan sistem berbasis website.

\section{B. Perancangan Sistem}

1. Perancangan Use Case Diagram

Berikut adalah use case diagram sistem informasi penjualan pada Smooth-Tee, 


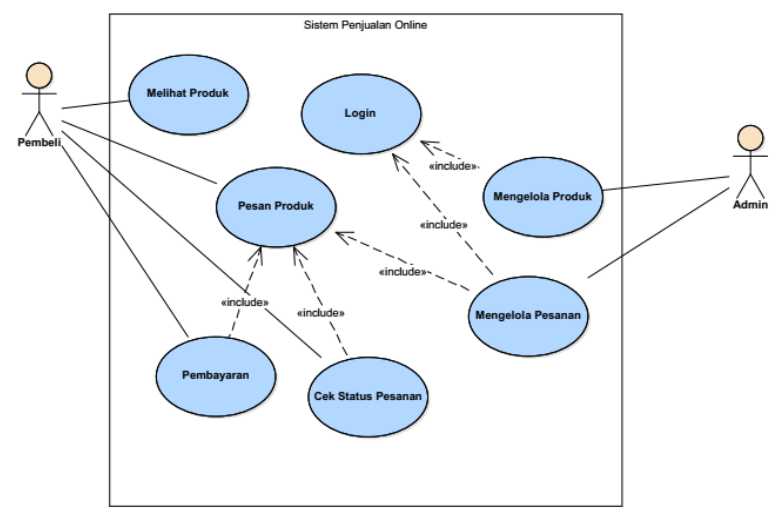

Sumber: Hasil Rancangan Penelitian

Gbr. 1 Use Case Diagram Penjualan

2. Perancangan Activity Diagram

Berikut adalah activity diagram sistem informasi penjualan pada Smooth-Tee,

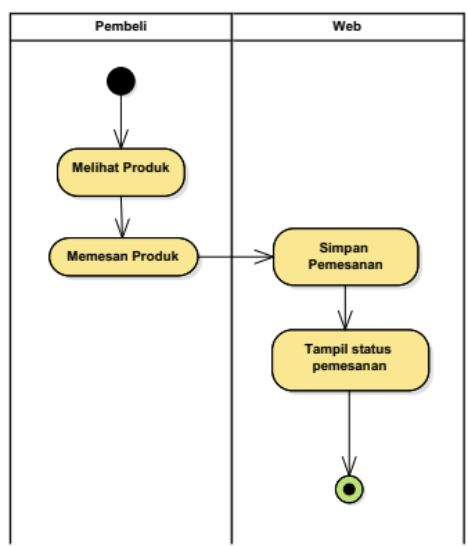

Sumber: Hasil Rancangan Penelitian

Gbr. 2 Activity Diagram Pemesanan Produk

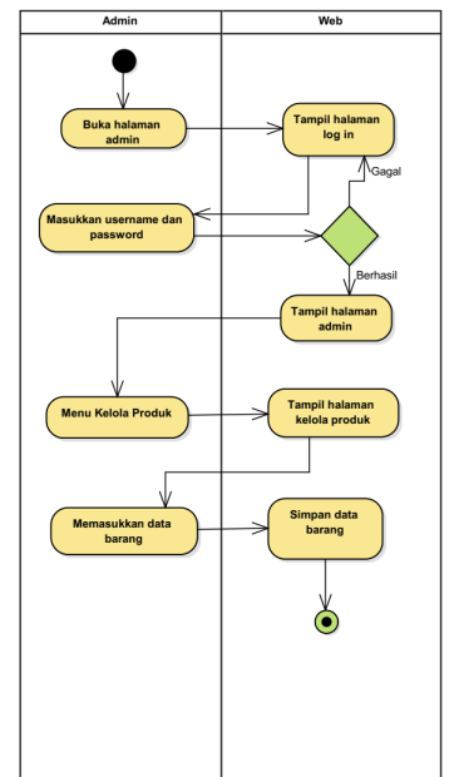

Sumber: Hasil Rancangan Penelitian

Gbr. 3 Activity Diagram Pengelolaan Produk

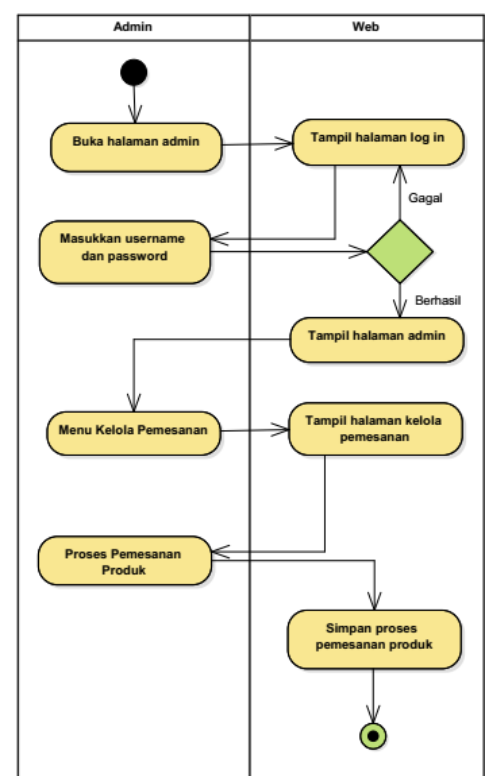

Sumber: Hasil Rancangan Penelitian

Gbr. 4 Activity Diagram Pengelolaan Pemesanan

3. Perancangan Activity Diagram

Berikut adalah class diagram sistem informasi penjualan pada Smooth-Tee, 


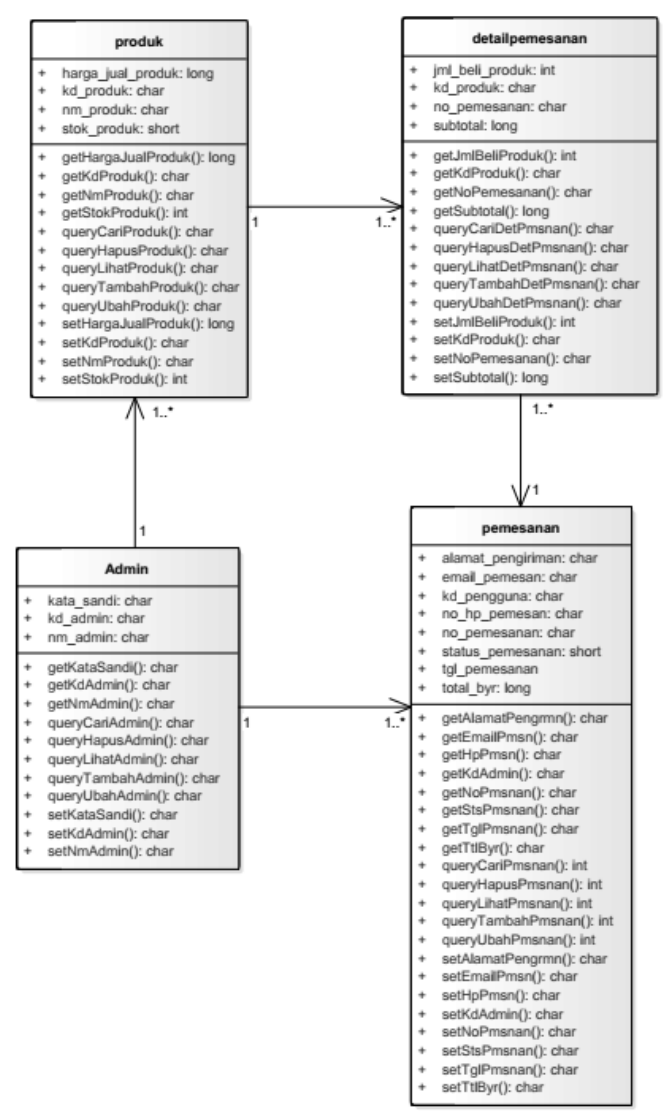

Sumber: Hasil Rancangan Penelitian

Gbr. 5 Class Diagram

\section{Desain Database}

a). ERD (Entity Relationship Diagram)

Entity Relationship Diagram menjelaskan hubungan antar data dalam basis data berdasarkan objek-objek dasar data yang mempunyai hubungan antar relasi.

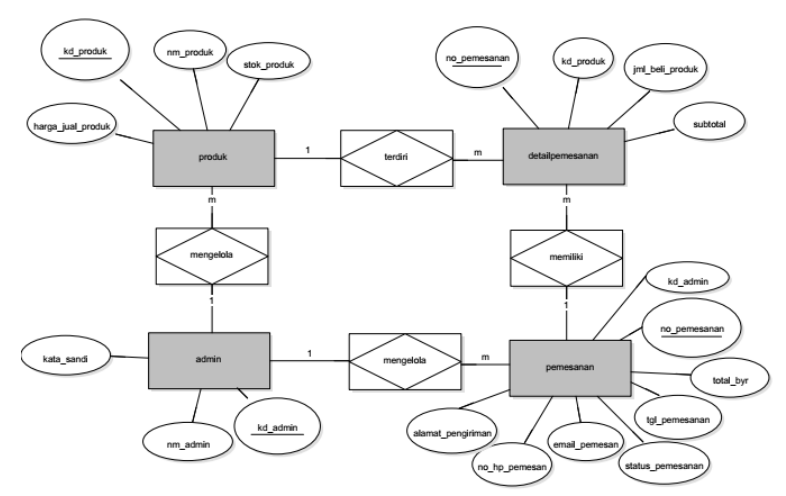

Sumber: Hasil Rancangan Penelitian Gbr. 6 Entity Relationship Diagram

C. Tampilan Website

1. Tampilan Halaman Login Admin

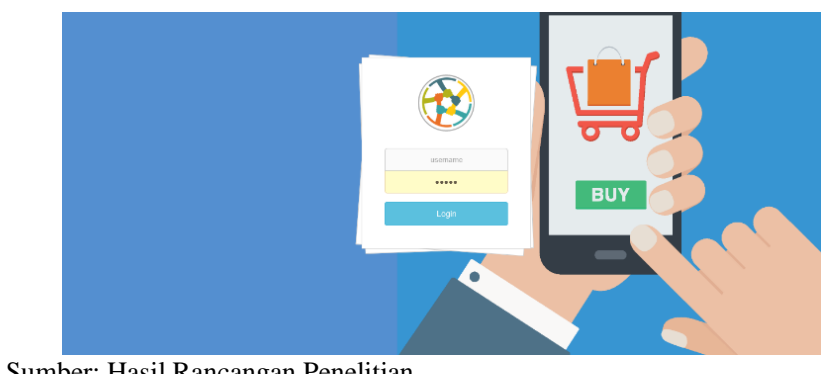

Sumber: Hasil Rancangan Penelitian

Gbr. 7 Tampilan Halaman Login Admin

2. Tampilan Halaman Pengelolaan Produk
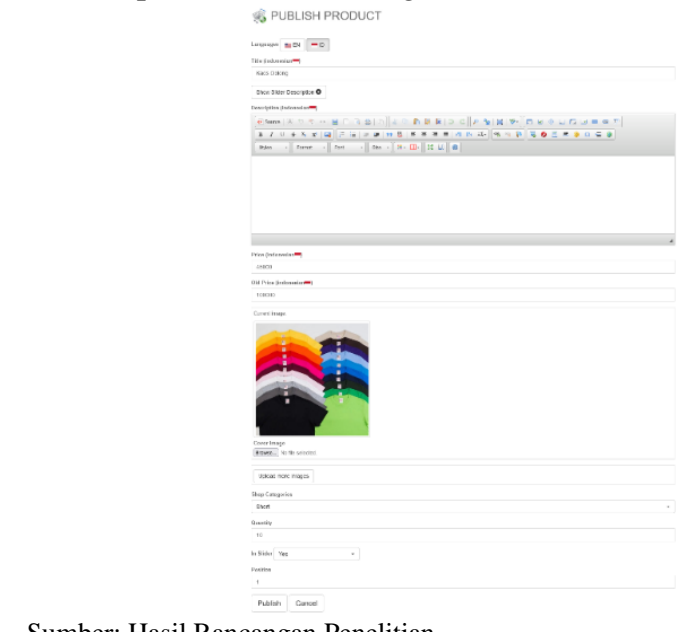

Gbr. 8 Tampilan Halaman Pengelolaan Produk

3. Tampilan Halaman Pengelolaan Pemesanan
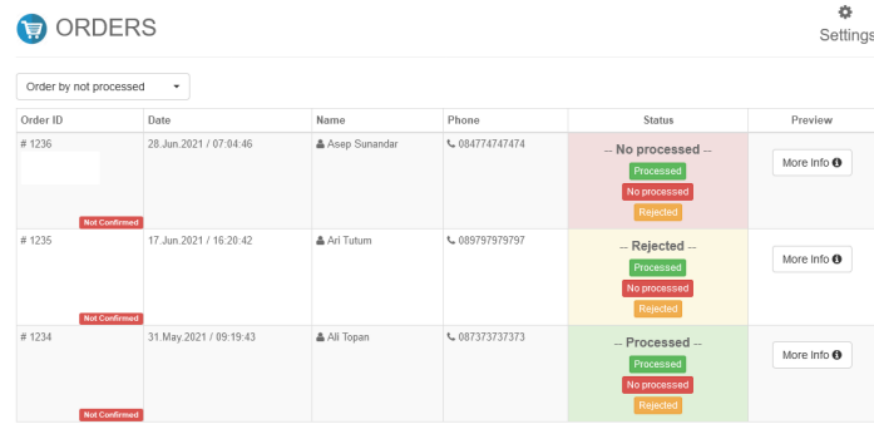

Sumber: Hasil Rancangan Penelitian

Gbr. 9 Tampilan Halaman Pengelolaan Pemesanan

4. Tampilan Halaman Utama 

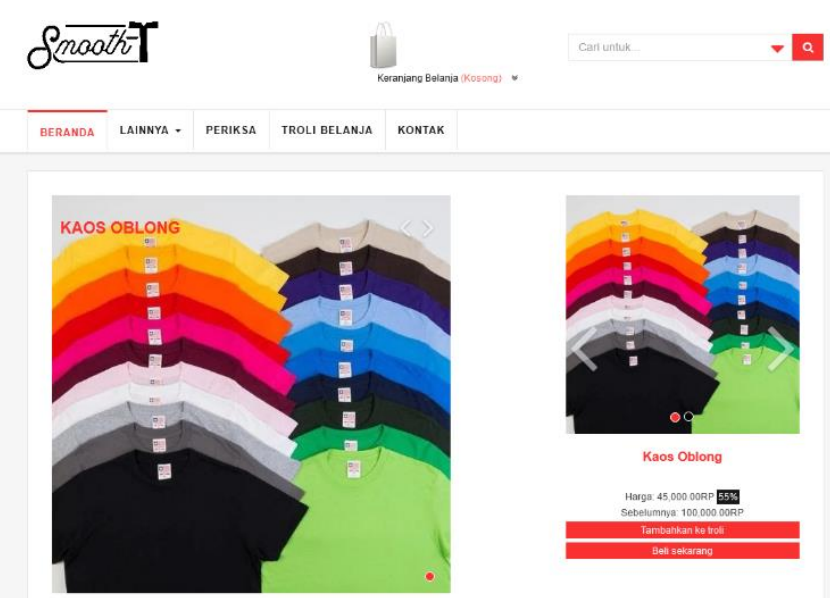

Sumber: Hasil Rancangan Penelitian

Gbr. 10 Tampilan Halaman Utama

5. Tampilan Halaman Transaksi

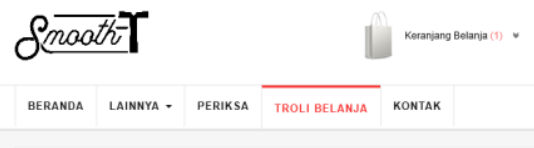

Troli Belanja

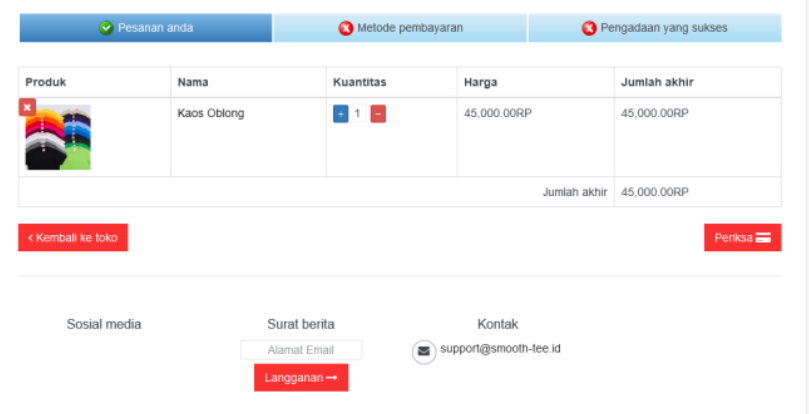

Sumber: Hasil Rancangan Penelitian

Gbr. 11 Tampilan Halaman Keranjang Belanja

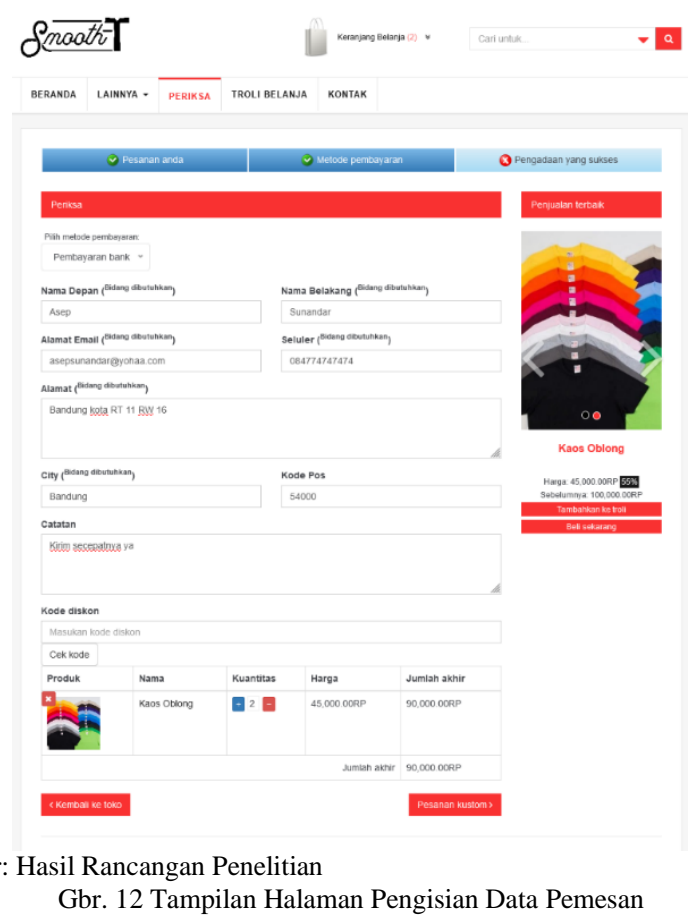

\section{KESIMPULAN}

Berdasarkan hasil analisis, implementasi dan penerapan Web yang telah penulis lakukan, maka ada beberapa kesimpulan yang dapat diambil. Adapun kesimpulan akhir dari tulisan ini adalah sebagai berikut:

A. Dengan adanya Website Smooth-tee diharapkan tercapainya akses informasi secara cepat dan keakuratan data.

B. Dengan adanya Website Smooth-tee dapat membantu promosi karena Website dapat diakses oleh siapa saja di mana saja tanpa batas ruang dan waktu asalkan terkoneksi ke internet. C. Dengan adanya Website Smooth-tee dapat membantu dalam pengolahan data berupa data persediaan barang serta data transaksi penjualan. 


\section{REFERENSI}

[1] G.W. Sasmito. Penerapan Metode Waterfall Pada Desain. Jurnal Pengembangan IT, Volume 2, No. 1, p. 8, 2017.

[2] J. Hutahean. Konsep Sistem Informasi. Yogyakarta: Deepublish, 2016.

[3] K. Yuliana, "Analisa Sistem Informasi Dan Pengembalian Buku Perpustakaan Pada SMA Nusantara," STMIK Raharja Jurusan Sistem Informasi, p. 48, 2018.

[4] T. Sutabri. Analisa Sistem Informasi. Yogyakarta: Andi Offset, 2012

[5] R. A. S and M, Shalahuddin, Rekayasa Perangkat Lunak Terstruktur dan Berorientasi Objek, Bandung: Informatika Bandung, 2016.

[6] Atom, "Activity Diagram," Studi Pustaka, 1210 2019. [Online]. Available: $\quad$ webstudi.site/2019/11/ActivityDiagram.html. [Accessed 1210 2019].

[7] Fajar Hariadi and Sukadi, "Perancangan Sistem Informasi Perpustakaan Pada Sekolah Dasar Negeri ukaharjo Pacitan," Indonesian Journal on Networking and Security, p. 1, 2013

[8] N. Fatimah and Yandria Elmasari, "Perancangan Sistem Informasi Perpustakaan Berbasis Web Untuk Sunan," JIP(Jurnal Ilmiah dan Penelitian Informasi, vol. 03, no. 02, p. 130, 2018

[9] D. PuspitaSARI, "Sistem Informasi Perpustakaan Sekolah Berbasis Web," Jurnal Pilar Nusa Mandiri, vol. XII, o. No.1, p. 228, 2016.

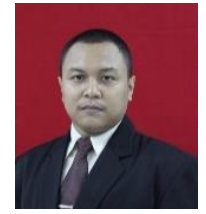

Aryo Tunjung Kusumo, M.Kom. Lahir pada tanggal 07 Maret 1986. Lulus dari Program Strata Satu (S1) Jurusan Sistem Informasi pada tahun 2009 dan Program Strata Dua (S2) bidang Ilmu Komputer konsentrasi E-Bussiness pada tahun 2015 di STMIK NUSA MANDIRI.

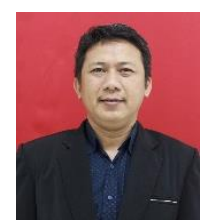

Vito Triantori, M.Kom. Lahir pada tanggal 24 Juni 1971 Lulus dari Program Strata Satu (S1) Jurusan Sistem Informasi pada tahun 1996 dan Program Strata Dua (S2) bidang Ilmu Komputer konsentrasi E-Bussiness pada tahun 2015 di STMIK NUSA MANDIRI.

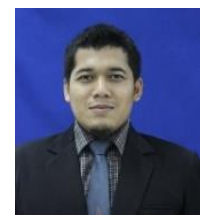

Ishak Komarudin, M.Kom. Lahir pada tanggal 19 September 1984. Lulus dari Program Strata Satu (S1) Jurusan Sistem Informasi pada tahun 2011 dan Program Strata Dua (S2) bidang Ilmu Komputer konsentrasi EBussiness pada tahun 2014 di STMIK NUSA MANDIRI. 